\title{
Communicating climate change: conduits, content, and
}

\section{consensus}

\begin{abstract}
Climate change has been the subject of increasing scientific efforts and growing interest from policymakers, international bodies and a variety of non-government organizations. The past decade has seen climate change in the headlines not only in conventional print and broadcast media but also in new electronic social fora. These developments have been aligned with shifts in the nature of climate change communication and with changes in how researchers study it and how a variety of actors try to influence it. This article situates the theory and practice of climate change communication within developments that have taken place since we first reviewed the field in 2009. These include the rise of new communication technologies, the development of new theories of science/climate communication, and the emergence of new climate communication practices. We focus in particular on continuing tensions between the desire on the part of communicators to inform the public and alternative strategies such as engaging stakeholders in dialogue. We also consider the tension between efforts to promote the idea of a consensus in climate science versus approaches that attempt to engage with uncertainty more fully. Throughout the article we explore the value of more participatory models of climate change communication that exploit, rather than shun, residual uncertainties in climate science in order to stimulate debate and deliberation.
\end{abstract}

\section{Introduction}

We drafted a first version of this article in $2009^{1}$ in the midst of events such as the failure of the UN Framework Convention on Climate Change Conference of the Parties in Copenhagen in 2009 (Conference of the Parties 15), Climategate ${ }^{2-6}$, numerous other '-gate' affairs ${ }^{7-9}$, and repercussions from a global recession which shifted ordinary people's attention and priorities from saving the planet to saving money. Around 2009 there was hope that 'better' climate change communication would increasingly and relatively straightforwardly lead to better global and local climate change policies and a popular uptake of such policies. Such hopes have been dented in the intervening years and public interest in climate change has dwindled, at least as measured through trends for search terms on Google ${ }^{10}$.

At the same time a different trend has emerged in scholarly attention to 'climate change communication'. Here one can observe an upward trend that accelerated after 2010 when our article was published. According to the Scopus database, as of May 2015, 311 articles have been published on 'climate change communication', with the most 'relevant' being our 2010 article entitled 'Theory and language of climate change' (cited 42 times on Scopus, 78 times on Google Scholar). 235 articles have appeared on the topic since the beginning of 2010. In this second edition of the article we do not attempt to review all these new articles, 
especially since searching Scopus for 'climate change communication' does not necessarily capture all articles on the topic and not at all more practical climate change communication activities. Instead, we have used three criteria to guide our decision on which literature to cover in this new review. First, we have sought to accommodate some of the developments in the subject area itself, for example the legacy of Climategate and how scientists, activists and communicators are addressing the so-called 'pause' or 'slowdown' in the predicted rise in surface and tropospheric temperatures. Second, we have sought to address the rise of social media such as Twitter. Third, we develop our 2010 critique of the transmission models of climate change communication via a critical review of the recent project to emphasise scientific consensus as a persuasive device in climate communication. Recently this has been a particularly prominent aspect of the approach concerned with providing the public with more information.

Therefore, a theme running through this paper is the tension between the classical idea in science communication that the public is uninformed and needs educating versus the paradigm that promotes the idea of engagement and critical, inclusive dialogue. When we were writing the original piece in 2009, a good deal of the effort made to communicate about climate change involved trying to find an optimum way of framing and wording messages so that the public would absorb them. Whilst a number of initiatives still proceed in this way, the growing presence of discussions of climate in new media and the spread of opportunities for interaction via these new platforms has provided researchers with novel ways of making sense of how climate change is collectively formulated, and, possibly, acted upon. Accordingly, it is timely to critically examine the work on this subject and assess the progress of different ways of thinking about scientist and activist warnings of climate change and their audiences in the broader public and in policymaking circles.

Finally, a further theme in our discussion concerns how climate change communication addresses the question of uncertainty. This is inherent in the differing levels of certainty the IPCC attaches to its conclusions and the calibrated language it uses to convey these to the wider public and policy makers ${ }^{11}$, as well as in the predictions of activists and communicators in the public sphere. There is a further tension in views about how uncertainty should be managed in a context where some try to minimize, or indeed maximize, uncertainty in public pronouncements, while others wish to accommodate a degree of uncertainty in climate dialogue. These tensions inform how the public is conceived and addressed, the kinds of communication that are deemed most desirable, and even the nature of messages themselves. In the following we first provide an overview of emerging trends in climate change communication and then home in on the themes of consensus and uncertainty. Some of what follows is based on current research undertaken by the authors, but most of this article is what one might call a critical, and necessarily selective, metaanalysis of recent work on climate change communication.

\section{New contexts for climate change communication}

After 2009, a period of soul-searching began about the nature of climate science, especially relating to issues of openness and transparency ${ }^{12}$, about the boundaries between science, 
politics and advocacy ${ }^{13,14}$ and about the politicisation and polarisation of the climate change debate ${ }^{15,16}$. The emergence of social media brought with it some hope of more democratic debates ${ }^{11}$, although opening up public spaces for debate has brought opportunities for incivility as well as deliberation ${ }^{17}$. In the process, the role of climate change communication in this treacherous science-politics landscape has come under increased scrutiny, with fundamental disagreements over whether it can be possible to communicate climate science in an apolitical way ${ }^{18,19}$.

In this context, a new science of science communication, of which climate change communication is a part, has emerged, informed by an increasing number of psychological studies trying to understand deep-rooted tensions that still characterise climate change debates and public attitudes to climate change. Alongside new theories, new practices of climate change communication rooted in some of these theories have been promoted (for an overview of this burgeoning literature, see Wibeck ${ }^{20}$ ), as well as new communication strategies such as consensus messaging.

In the following, we first summarize some older and newer results derived from analyses of traditional media coverage of climate change, followed by newer and ongoing research into online debates on climate change. We then present a brief summary of some psychological studies of climate change communication which have been carried out alongside extensive surveys of public attitudes, which fed into new theories of science and climate change communication and influenced practical climate change messaging and outreach activities.

\section{Climate change communication: Theory, practice and controversy}

\section{Traditional media}

While traditional media analysis is still a buoyant subfield within climate change communication research, online media analysis has begun to attract increasing scholarly attention ${ }^{21}$. We first summarize some recent contributions to the older field of study dealing with traditional media and then turn our attention to the newer field dealing with climate change debates in the social media.

In $2014{ }^{22}$, a meta-analysis of 133 studies of the role of media in climate change communication showed that research activity had increased in quantity and broadened in scope, including more countries, more types of media, and different methodological approaches. Within this burgeoning literature, Western countries and print media continued to be the dominant research topics ${ }^{22}$, although broader, international analyses are now beginning to appear. For example, a comparison between 27 countries showed that climate change coverage increased in all countries between 1996 and 2010, although there were significant differences between countries in the extent of growth and media attention ${ }^{23}$. However, since this period there have been signs of reversal in these trends as late 2009 marked a peak in print media coverage of climate change, with both the Copenhagen summit and Climategate prompting large number of stories ${ }^{21}$. The big picture has been of declining media interest since these events ${ }^{24}$ although there have been recent spikes in interest, especially around extreme weather events, IPCC reports and new developments in 
climate policy and politics ${ }^{21}$. This suggests that the Paris climate summit in late 2015 (Conference of the Parties 21) may see a significant increase in media attention.

Since 2010, country specific and comparative studies of media coverage have flourished ${ }^{25}$, with one international study showing that political advocates for climate policy have been far more visible in media articles than skeptical voices ${ }^{26}$. Another study found that while in most UK newspaper climate change is accepted as a problem and political solutions to addressing it are being discussed, some newspapers in the U.S. still discuss whether climate change is a scientific problem or not ${ }^{25}$.

This provides an insight into how climate change has become an increasingly politicized subject since its arrival on the public agenda in $1988^{27}$. For example, a content analysis of articles published in the New York Times ${ }^{28}$ found "a gradual decline in the volume of material within the 'Science' topic and an expansion of themes classified under the 'Politics' topic" between 1995 and 2010. After 2010 there was an increase in discussions around mitigation technologies from carbon capture and storage to fracking, alongside a hope that new types of technologies such as fracking, might allow a breathing space for thinking about future ways of reducing carbon emissions ${ }^{29,30}$. Allied to this, there have been a number of detailed studies of the metaphorical framing and social representations of climate-related issues such as geoengineering ${ }^{31}$, carbon capture and storage ${ }^{32}$ and fracking ${ }^{33-35}$. Ongoing attempts to overcome the abstract nature of scientific knowledge have also led the study of visualization ${ }^{36}$ and press conferences ${ }^{37}$ to emerge as sub-fields of climate change communication research.

Such moves from abstract science to the material mitigation (and increasingly adaptation) involve complex interactions between the producers and consumers of media texts, giving climate change different meanings in different places at different times. This context-specific making and re-making of climate change meaning has been described as a 'circuit of culture' ${ }^{38}$, which contrasts with the globalized visions of climate change that have percolated into society from climate science ${ }^{39}$. In the decade since this paper's publication, the cultural circuit of media communications about climate change has changed dramatically. As well as the shift from the abstract/scientific to the material/political, the structures within which meaning-making takes place have changed, with the dominance of mainstream media being eroded by interactive, social media.

\section{Social media}

Whilst climate issues still feature in the mainstream media, the online environment has provided a new and expanding arena for such discussions. Climate scientists have taken to blogs, Twitter and other social media platforms to enter into dialogue with a diverse range of actors including colleagues in their own professional communities, political activists, and 'lay' publics ${ }^{40,41}$. This has opened up new areas of research around the role of the internet in efforts to engage with multiple audiences and evaluate how different stakeholders participate in online debates ${ }^{42}$.

One of the first applied linguists to study blogs in the context of climate change communication was Koteyko ${ }^{43}$. She argues that for scholars interested in studying the 
conceptualizations of climate change, blog discussions provide a rich source of data due to their relative spontaneity, interactivity, and multiple possibilities for content creation, enabling a large number of voices that can be analysed almost in real time. Here the internet is viewed as a rhetorical context providing publics with the opportunity to engage with developments in science and policy, and contest elite messages ${ }^{44}$. Koteyko et al. ${ }^{45}$ further demonstrate how climate change communication scholars can systematically retrieve data from blogs and apply text analysis and data visualisation tools to establish both macro- and micro-patterns of language use by different discourse communities., For example, US states with Republican voting patterns have been found to be more likely to originate Twitter comments using the term 'global warming' and frame it as a 'hoax' than were states with a preponderance of Democrat voters, where the term 'climate change' was more apt to be used and was framed as a real problem requiring attention ${ }^{46}$.

Discussions on blogs platforms enable spaces for rhetorical invention which can foster discussion, reveal instances of contestation and help generate alternative networks of scientific knowledge production. Blogs were a key influence on newspapers in the creation of media hype around Climategate, both in terms of the level of attention afforded to the controversy and the type of language being used ${ }^{47}$. Sharman ${ }^{48}$ critically examines the climate skeptical blogosphere investigating whether a focus on particular themes contributes to the positioning of the most central blogs. More recently, a large-scale analysis of the English-language blogosphere combined content analysis of topics with study of the network structure ${ }^{49}$. Moving beyond the polarized view of climate change debate, the authors examined nuanced differences between skeptics and accepter communities on the blogs and identify one large community of sceptics and several climate change accepter communities. Meanwhile, Matthews ${ }^{50}$ provides a useful insight into the reasoning of those who publicly question climate science on blogs. Furthermore, comments left underneath blogs or online newspaper articles provide insights into the meanings given to climate change by readers beyond elite media discourses ${ }^{11,51}$. This pluralisation of meanings is consistent with climate change's shift from the scientific to the political, but also poses a challenge for 'moderation' between individuals approaching the issue from different cultural and political perspectives ${ }^{52}$. This highlights the importance of both the dynamics and contexts for online participation in climate change discussions, and the complex interplay between the social, instrumental, and technological determinants of participation ${ }^{53}$.

Perhaps as a reaction to the increasing role of politics in discussions about climate change there have come calls for increased communication from scientists ${ }^{40}$, who have often been peripheral figures in online debates about climate science and climate politics ${ }^{54}$. Schäfer emphasizes that increasing the number of stakeholders involved in online discussions has not improved the robustness of scientific information available or the quality of the debates, although also noting that "impacts on the broader public seem to be limited so far" 54 . A small number of climate scientists have used blogs to communicate a variety of aspects of knowledge which are less evident in formal scientific publications for a number of years ${ }^{55}$.

Recent studies suggest that the number of climate scientists participating in social media conversations is also beginning to increase. For example, an analysis of postings on Twitter around the publication of the IPCC's report into the physical science basis of climate change 
(Assessment Report 5, Working Group 1) showed physical scientists and social scientists participating in conversations with journalists, activists, NGOs and members of the public ${ }^{56}$. The analysis coded conversation participants on Twitter according to whether or not they expressed support for the IPCC, and found that the densest network of conversational connections occurred between individuals in the UK and Europe with contesting views. A study of Twitter messages containing generic hashtags about climate change ${ }^{57}$ found some similar "open forums" of contestation, but concluded that discussions were more likely to take place within more homogenous enclaves of opinion. The authors conclude that "Overall, social media discussions of climate change often occur within polarized 'echo chambers'". Such studies suggest that it is possible for online communities to contribute both to bipartisan engagement as well as enabling polarization. However, quantitative 'big data' analysis needs to be treated with caution, as it can become abstracted and divorced from key contexts which give social media postings their meaning(s) ${ }^{58}$. For social media analysis to realize its full potential, quantitative analysis must be undertaken in tandem with qualitative, ethnographic analysis of social media postings and interactions. Notwithstanding these methodological observations, in the next section we consider some attempts to explore the psychosocial and cultural factors that may influence perceptions and communication of climate change.

\section{Psychology, politics and practice}

Climate change communication researchers, psychologists in particular, have begun to study the wide spectrum of voices and views in the climate change debate. Whilst many participants are broadly aligned with the position espoused by the IPCC, there are others who consider the impending changes are likely to be more catastrophic and immediate, and some who whole-heartedly reject the idea of anthropogenic climate change. Equally, it is possible to find constituencies endorsing climate change policies, mainly focusing on mitigation, whereas others reject such policies but sometimes endorse adaptation measures ${ }^{48,59}$. Such plurality of views have prompted contrasting strands of applied research, focusing either on dispelling climate change 'myths' ${ }^{60}$ or trying to create a space for a more open dialogue in which various voices and opinions can participate ${ }^{61,62}$. In the following we shall first summarise some aspects of the psychological and historical efforts being made to gain insights into changes in climate change communication and then go on to detail some more applied efforts at climate change communication informed by such studies and other survey-based approaches.

Within research programmes focused on psychological issues, efforts are made to understand the political and cultural roots of diverse attitudes to climate change. Several recent studies focus on message content and cognitive and attitudinal variables to provide insights into climate change communication. Bain et al. ${ }^{63}$ found that, in the U.S., those skeptical of anthropogenic climate change were more likely to support environmental actions if these were justified in terms of economic benefits or making people more considerate of one another. Focus on hope and potential solutions can be more effective in inducing support for mitigation policies if the audience is initially skeptical ${ }^{64}$. Messages 
focusing on technical solutions promote less polarization in recipients. Messages focusing on fear and predictions of adverse events can increase skepticism, perhaps because they disrupt underlying 'just world' beliefs, and can reduce people's intentions to perform mitigating actions ${ }^{65}$. A U.S. study ${ }^{66}$ suggests that news about potential adverse effects may motivate liberals towards mitigating actions action but may make conservatives more skeptical.

These studies suggest that there is no single message that will appeal to all political persuasions. Neither is it simply a matter of providing people with scientific information: in the U.S., conservative skeptics may be well informed ${ }^{64}$ and scientifically literate ${ }^{67}$. To address these kinds of complexities some authors have attempted to condense and summarize the findings and produce what one may call 'best practice guides'. One of the best-known of these guides showed that "in order for climate science information to be fully absorbed by audiences, it must be actively communicated with appropriate language, metaphor, and analogy; combined with narrative storytelling; made vivid through visual imagery and experiential scenarios; balanced with scientific information; and delivered by trusted messengers in group settings" ${ }^{68}$. Such strategic climate change communication relies not only on psychological studies but also on increasingly sophisticated opinion polls ${ }^{69}$. Such research is applied 'in the field' by outreach organizations such as Climate Communication in the US who aim to make science "heard and understood"70, and the Climate Outreach and Information Network (COIN) ${ }^{71}$ and the Talking Climate ${ }^{72}$ website in the UK. The latter is novel in providing a bridge between climate change communication academics and practitioners, providing updates on the latest academic research and considering how this should inform practice.

Much applied work focuses on finding the most effective means by which climate science communicators can persuade the public of the importance of climate change. Discovering such means is believed to lie in a greater understanding of the affective, cognitive and attitudinal variables that provide cues for effective communication. An example of such an endeavor is the Time for Change? ${ }^{19}$ report on climate change communication, a collaboration between climate scientists, policy analysts and Science and Technology Studies scholars. The report focuses on the role of climate scientists in contributing to public and policy discourse and decision-making on climate change. It recommends the establishment of a "professional body for climate scientists [...] to provide a unifying purpose and to offer leadership". It also advocates training for climate scientists in how to engage in communication more transparently and to ideally see it is as an opportunity for 'coproduction'. The authors commend that "[a]ctive critical self-reflection and humility when interacting with others should become the cultural norm on the part of all participants in the climate discourse." The report places the onus of communicating 'policy-relevant' climate science on the shoulders of the scientists themselves, a potentially risky strategy as communication efforts coming from those perceived by some to be 'an interested party"73 might not necessarily be well received. However, this seems likely to be a problem to be dealt with rather than avoided; climate science is entangled with multiple ideas about how our societies may look in the future so has inevitably become a site of politics and constestation ${ }^{74,75}$. Perhaps more problematic is the report's call for a climate science 'metanarrative', echoing calls elsewhere for scientists to "speak with one voice"76. As we argue in 
the next section, attempts to formulate a unified narrative are unlikely to yield a solution to climate change communication dilemmas.

\section{Consensus messaging}

An increasingly prominent example of a unified climate communication message, involves the formulation and dissemination of a scientific 'consensus' on anthropogenic climate change. We place a particular focus on consensus messaging for academic and practical reasons. Academically, consensus messaging marks a continuation of key assumptions regarding the relationship between science and public from previous science communication models that see the public as needing to be informed and persuaded. Practically, consensus messaging has become increasingly visible in recent years, with a high profile academic article claiming that $97.1 \%$ of academic papers expressing a position on climate change either explicitly state or imply that warming has taken place and has been primarily caused by human activities ${ }^{77}$. The paper's authors have sought to increase the impact of their paper through the 'Consensus Project' that aims to "communicate the overwhelming scientific agreement on anthropogenic (human-caused) global warming to the public at large" ${ }^{78}$.

The "97\%" claim has become a climate change communication meme, inspiring a blog ${ }^{79}$, a popular television comedy programme ${ }^{80}$ and even being tweeted by President Barack Obama, albeit embellishing the original claim by asserting that the consensus was about "dangerous" climate change ${ }^{81}$. The Consensus Project is justified by the reported existence of a 'consensus gap' between the quantified level of consensus in the scientific literature and the awareness of this consensus in the general public (as measured through opinion polling), which is believed to constitute a "roadblock that has for two decades inhibited public support for climate action" ${ }^{82}$. This is an example of the classical technique of 'argument from authority', where the credibility and authority of climate science is invoked as a means of persuasion. Two academic papers support this approach, providing evidence of correlation between awareness of the scientific consensus and support for climate policy 83 , and which showed that supplying information about the $97 \%$ consensus to a sample of pedestrians increased their acceptance of anthropogenic global warming ${ }^{84}$. This evidence, in conjunction with the Consensus Project's extensive media coverage ${ }^{85}$ might confirm the value of this strategy against what some call the 'Merchants of Doubt' ${ }^{\prime 86}$. However, evidence from within psychology and other disciplines suggests a note of caution.

First, within psychology there is an argument that the $97 \%$ strategy fails to take into account the importance of cultural effects on assimilation of information, and that as members of the public take up more entrenched positions on climate change, increasing the supply of information about climate science may have less success ${ }^{87}$. Second, exploring correlation between variables and conducting laboratory studies cannot supply definitive evidence about climate change communication strategies. Science communication takes place in an open system, where competing messages exist. Even if the merchants of doubt disappeared, many other concerns will continue to compete for the attention of publics, diluting the immediate focus placed on climate change in laboratory studies ${ }^{88}$. Kahan ${ }^{89}$ argues that the Consensus Project failed to provide significant new information about consensus in climate science ${ }^{90-93}$, and that media coverage of previous consensus studies failed to increase the 
percentage of the public who believes that humans are mostly responsible for recent increases in the Earth's temperature: "Such a strategy has already been tried in the real world. It didn't work."

Third, by putting science at the front and centre of communication efforts, advocates of the 97\% strategy place science in the firing line of those who oppose particular climate policies. This focus on science is not restricted to climate communicators; the UK's Climate Change Act ${ }^{94}$ states that the national target for reducing carbon emissions can only be amended with "significant developments in scientific knowledge about climate change, or European or international law or policy". When science, rather than democratic political engagement, becomes the main plank upon which policy is built, it is unsurprising that science becomes a target for political opponents of policy. As Demeritt ${ }^{95}$ presciently argued, attempts to substitute climate science for climate politics merely prolongs the debate over whether or not the science is 'sound'. Within this context, the importance of the various '-gates' becomes apparent, as they derail science-focused communication efforts. It may be that climate communicators who focus on science are taking their cues from an assumption that scientific consensus begets political consensus $39,75,95$. However, as well as being poorly founded in the evidence, such an assumption may also be damaging to attempts to address climate change: the causes and consequences of climate change are likely to be diverse, suggesting a multiplicity of ways in which problems related to climate change should be addressed.

A focus upon the encomium of $97 \%$ consensus tends to restrict discussion in the public sphere to those areas where substantial consensus can be mustered, such as whether warming has taken place or the presence of an anthropogenic component. It may be more difficult to address the diversity of processes and mechanisms which contribute to periods of change or stability in climate, such as ocean processes ${ }^{96}$, the role of volcanic activity ${ }^{97}$, or the ongoing concerns about relationships between climate models and instrumental records and the extent to which these differ ${ }^{98}$. In other words, it focuses discussion on areas of high consensus rather than areas of complexity.

Perhaps then, a useful direction in communication about climate is to focus not only on consensus but to seek to celebrate the disagreements which necessarily flow from such a complex multi-level issue as climate change ${ }^{99}$. Such an overtly political approach to climate change communication accepts both that hard-to-overcome cultural barriers exist in talking about many aspects of climate change (including climate science), and that dialogue which is inclusive of human values provides greater promise than top-down efforts at science education ${ }^{87}$. Recent reports aimed at practitioners of science communication have offered advice on knitting together both values and scientific knowledge ${ }^{100,101}$ with an understanding of the importance of "put[ting] yourself in the audience's shoes"102. Experts tend to see the public as having a limited grasp of uncertainty - hence the appeal of 'consensus' - but there are many examples of phenomena where laypeople think effectively about uncertainties, such as in sport or gambling ${ }^{103}$.

\section{Climate change communication and the deficit trap}


It is worth pausing at this point to reflect further on the kind of models of science and the public implied in many of the efforts described above to inform and persuade the public. Like the older 'deficit' models of science communication, there is an underlying assumption that the public is somehow lacking in knowledge or is insufficiently aware of impending dangers. In this view the job of the scientist or science communicator is to persuade the public into alignment with the kind of consensus promoted by the Consensus Project ${ }^{77,82}$. This model of the public as deficient and as a body that needs to be educated and persuaded underlies a great deal of advice about climate communication. This is what we might describe as the traditional paradigm of science communication which itself is founded on the deficit model of public understanding of science ${ }^{104}$.

For example, in a short but spirited article Hassol ${ }^{105}$ describes several such techniques whereby scientists can communicate in terms akin to those understood by putative members of the public, including metaphors and simple story telling. This focus on telling stories in simple terms and repeating simple messages is pursued further by Somerville and Hassol ${ }^{106}$ and also combined with consensus messaging. Whilst this project is ongoing, as we have noted before, scientific communication is about rather more than simply well-chosen metaphors or stories judged sufficiently simple for the public to assimilate ${ }^{107}$. As Wynne ${ }^{108}$ notes, these themselves can be read back to disclose how scientists conceive of the public. Indeed, this preoccupation with finding the language of the common man or woman as a vehicle of public engagement is perhaps the latest manifestation of the older concern that the public is somehow deficient in knowledge ${ }^{109}$.

According to this view, alignment between the public and the putative scientific consensus will be enhanced if more colloquial language is adopted, recognizing the variations in meaning across social groups. Once again, however, in this view, the scientific framing of the issue and the public's ignorance is taken for granted and the stage is set for the kind of manipulation of publics to a scientific agenda described by Cooke and Kothari ${ }^{110}$. Instead, argue Felt and Wynne ${ }^{111}$, it might be possible to conceive of a different model of communication and engagement which allows a more dynamic relationship to develop and enables participants to 'challenge entrenched assumptions, interests, power-structures and imaginations' and more fully cognizant of the capabilities of people to deliberate, discuss and deduce solutions independent of interventions from experts and governments. Such a model runs contrary to the assumptions of the old public understanding of science model which are encoded in the Consensus Project and the work of Hassol: the public as a body in need of enlightenment and persuasion by 'experts'. This, as Felt and Wynne ${ }^{111}$ describe, suggests that "interest seems focused on new procedures more to justify established imaginations and commitments, and to procure 'trust' for what remain essentially unchanged imaginations, habits-of-thought and decision-making processes". It reflects "persistently technocratic, reductionist and exclusive functioning of the underlying governance culture itself". Felt and Wynne remain optimistic that a more effective and creative dialogue is possible, with the recognition that science and government are part of the very societies they seek to control. The response is to focus on "'opening up' the ways in which the 'answers' depend on the 'questions' and the framing of analysis... [to] facilitate the nurturing and maturing of more open and diversely creative discursive spaces on the roles and purposes of science in governance"112. 
Many studies reviewed here are rooted in 'visions of effective climate change communication' which draw on such communication maxims as the importance of engaging people emotionally, carefully defining communication goals and knowing one's audiences. Even where dialogue is advocated, this is often formulated in an expert-informed manner and experts are the arbiters of reality. As we have described, and as critics of simple public understanding of science models such as Wynne ${ }^{113}$ have pointed out, there often exists in these approaches an implicit model of the audience which may not be subject to empirical scrutiny - a kind of expert 'folk model' ${ }^{103}$ - and which may assume from the outset a degree of ignorance or deficit. We argue that this is a poor perspective from which to undertake dialogue, a position supported by a first-hand account from three climate scientists active on social media: "online conversations can be unpredictable, rambunctious and frustrating, they are often personally and professionally rewarding ... conversations are more successful than lessons" ${ }^{\prime 4}$.

Sidebar title: Communicating uncertainty and localizing climate change communication
One of the most pressing issues is how scientists and communicators address the question
of uncertainty and complexity. Climate scientists, climate communicators and social
scientists are beginning to debate uncertainty and complexity more openly. These activities
need to continue alongside consensus messages, as only in this way suspicions that linger
about the scientific process can be overcome. Alongside such activities, more local climate
change communication activities are necessary, as it is at the local rather than the global one
that scientific uncertainties, especially about risks and impacts, persist and have to be
discussed openly and honestly.

Sidebar title: Rethinking 'effective communication': lessons from 2010

A key finding of our 2010 review was that much of the literature sought to present "visions of effective climate change communication" based on assessments of communication audience, style and goals. We also found that finding the right words, metaphors and strategies with which to communicate is necessary, but insufficient for good public engagement. These findings remain valid today and in light of our review of more recent climate change communication literature.

Communication does not exist in a vacuum: audiences hold particular values and views which will influence their interpretation of new information. Rather than assuming such influences to be nefarious and in need of correction, we identified the importance of twoway dialogue and lively debate as inherent to productive deliberation about possible futures in a changing climate. The implication of this finding for future research is that studies of climate communication 'in the field' should be given greater weight than laboratory-based studies aimed at behaviour change.

\section{Four Future Directions}


Anticipating future challenges and developments in dialogues about the world's climate is as difficult as predicting the climate itself. Nevertheless it is possible to point to four future directions for climate change communication research and practice.

First, one of the most pressing issues is how scientists and communicators address the question of uncertainty and complexity ${ }^{114}$. Echoing Somerville and Hassol's $\mathrm{s}^{106}$ enthusiasm for simple messages, sometimes experts are wary of including complexity and uncertainty in public discussions of climate change. Such a view is also expressed by some journalists, such as James Randerson speaking to the House of Commons Science and Technology Committee where he expresses concern about the possibility that doubt might be sown and the risks of 'playing up uncertainties' ${ }^{\prime 15}$. Yet as Wynne ${ }^{116}$ reminds us, and as some climate scientists are beginning to advocate themselves ${ }^{117}$, indeterminacy is a central part of human inquiry. Indeed, many of the key parameters in climate change, like temperature records, climate sensitivity values or ocean heat content estimates are complex human constructions in terms of how they are assembled, what they mean and their political trajectories as they are used by scientists and other interest groups. Rather than simply being objects of scientific discovery, these might best be seen as "epistemologically and indeed ethically complex, strictly indeterminate, heuristics" ${ }^{116}$. This is not to undermine the case for action, but rather to advocate a richer understanding of human processes in discovery, dissemination and political decision making than is often found at present.

There is also a practical benefit to addressing uncertainty. At the moment, a curious individual browsing the internet for information on topics such as the degree of uncertainty attached to environmental measurements, the role of adjustments and missing data in temperature records or comparing present day weather events with those of the past, are likely to encounter people skeptical of mainstream scientific claims on these issues. This means that robust and persuasive accounts of the processes involved in creating data sets and the measures of uncertainty attached to these would be a valuable part of the argument from the point of view of those seeking to deploy these factors in public discussion. Many key variables are complex assemblages inferred from a variety of primary data sources and are, as Wynne reminds us, epistemologically and ethically complex too ${ }^{116}$.

Second, as well as emotionally charged predictions of dramatic change, it is important to find a way of talking about relatively gradual processes or periods of stability. For example, predictions of comparatively modest change in temperatures over the next few years are arising from a variety of sources such as the UK Met Office's decadal forecasts and from studies of ocean processes ${ }^{118}$. Similarly, the so called 'pause' or 'hiatus' in temperature rise in recent years has prompted discussion in both lay and academic circles. One communication strategy is exemplified by Michael Mann in Scientific American ${ }^{119}$, namely to describe this as a 'faux pause' and reaffirm predictions of accelerated and dangerous warming in the near future. Some concerned commentators have even suggested that discussing the 'pause' represents a hazardous 'seepage' of climate sceptics' agendas into the academic sphere ${ }^{120}$. Yet this is only part of the story. Rather than being a distraction from the overall narrative of impending peril, discrepancies and anomalies are often integral to scientific observation and academic discourse ${ }^{121}$. Some climate scientists and media analysts have taken up the opportunity provided by the 'pause' to encourage more diverse climate 
change communication strategies and to encourage rather than distract from uncertainty communication $40,117,122$. However, more overt engagement with them could render "public lives, public uptakes, and public engagements more resilient, and practically rewarding"116.

In the light of these two issues, we would like to repeat our plea for policymakers, scientists and communicators to look beyond simple transmission models or public understanding models of the relationship between expert knowledge and 'lay knowledge'. These embody a limited view of the relationships between science and society, a limited view of the public and curiously truncated view also of communications research as being about finding the right words and checking if people have listened. They may also, as Welsh and Wynne caution ${ }^{123}$, actually help to create a public which is passive and apparently ill-informed. Studying how the competing voices of climate change are framed by various stakeholders in different media (from print media to Web. 2.0) can help gauge public opinions and reactions to the issue of climate change and its mitigation. Whereas traditional media such as newspapers have been extensively studied, attempts to examine the construction of climate mitigation issues in emergent social groups, blogs and other new media are still relatively uncharted territory ${ }^{124}$. These proliferating sites of debate, engagement and knowledge construction offer new ways of thinking about climate change and its attendant risks. They offer the possibility that each case can 'develop its own logic of participation'111 and new actors can develop their own voices and their own ways of harnessing science and technology.

Third, the study of climate change communication itself can change the social landscape. New ways of thinking about politics, power and social structure are afforded by discussions of climate change ${ }^{125,126}$. Darier and Schüle ${ }^{127}$ found that awareness of global environmental issues is always contextualized in broader perspectives and is not exclusively 'environmental' and may be informed by features of national cultures. Although studies of public perceptions cannot directly tell policy makers which specific policy initiatives could work in practice, they can, however, give indications of what is likely to be acceptable to citizens, and more importantly why or why not.

Fourth, it is valuable to recognize that there may not be a single effective way to communicate about climate change to all audiences. To this end, rather than seeing the public as a body of people whose opinions need to be guided, there are promising areas of work where studies of public perceptions and commitments inform the framing of messages and what they should say. Using this method, a team of researchers ${ }^{128}{ }^{129}$ examined public understanding and perception of climate change to develop a brochure for the general public, which was iteratively refined via discussion with the audience. Studies of public perceptions ${ }^{130-132}$ can provide evidence of what people currently know and believe about energy technologies, with the goal of facilitating better communication between all parties about the respective risks and benefits of climate change. Lorenzoni and Hulme ${ }^{133}$ discussed several future scenarios with participants and elicited a desire on the part of their informants to see more information about how the predictions were derived and the kinds of evidence they were based upon, also uncovering questions of trust and a wish to explore the shorter-term local impact of possible changes. Such findings chime with our earlier plea 
for more effective engagement with the detailed processes of how measures and predictions are compiled and arrived at.

\section{Conclusion}

In summary, rather than seeing the audience as in need of instruction from expert communicators, maybe the best way forward is to grasp the possibilities offered by a more inclusive model of the policymaking process. Rather than being passive recipients of communication designed to ensure that they are 'on message', once people become collectively engaged with a task that they have a realistic chance of solving, they can, acquire knowledge and technologies themselves. This process has been theorized through the notion of discursive or deliberative democracy ${ }^{134,135}$ and through the notion that technologies change social relationships and that these in turn modify the technologies ${ }^{136}$. More radically, it may be that we should actively embrace sources of dissensus, rather than consensus, as they provide a fruitful means of reaching decisions within democratic societies ${ }^{99}$. Such sources of dissensus are likely to include deeply rooted cultural and political values ${ }^{67,}$ 100,102 which are unlikely to be reconcilable, but must be treated seriously and as legitimate within a properly functioning democracy ${ }^{137}$. A lively debate with acknowledgement of difference and uncertainty can best be understood not as a failure of consensus or a deficiency of knowledge but as a means of 'keeping public engagement with science authentically alive and not under the control of agents whose own culturally embedded assumptions, imaginations and practices may well be part of the problem ${ }^{\prime 111}$.

\section{WORD COUNT: 6845}

\section{Acknowledgement:}

Warren Pearce and Brigitte Nerlich acknowledge the support of the Leverhulme Trust through the Making Science Public programme (RP2011-SP-013). The original 2010 article was supported through funding from the Economic and Social Research Council (RES-062-231256).

\section{References}

1. Nerlich B, Koteyko N, Brown B. Theory and language of climate change communication. Wiley Interdisciplinary Reviews: Climate Change 2010, 1:97-110.

2. Norton DW. Constructing "Climategate" and Tracking Chatter in an Age of Web n. 0. 2010.

3. Holliman R. Advocacy in the tail: Exploring the implications of 'climategate' for science journalism and public debate in the digital age. Journalism 2011, 12:832-846.

4. Maibach E, Leiserowitz A, Cobb S, Shank M, Cobb KM, Gulledge J. The legacy of climategate: undermining or revitalizing climate science and policy? Wiley Interdisciplinary Reviews: Climate Change 2012, 3:289-295.

5. Grundmann R. The legacy of Climategate: revitalizing or undermining climate science and policy? Wiley Interdisciplinary Reviews: Climate Change 2012, 3:281-288.

6. Nerlich B. 'Climategate': Paradoxical metaphors and political paralysis. Environmental Values 2010, 19:419-442.

7. Mahony M. The predictive state: Science, territory and the future of the Indian climate. Social Studies of Science 2013:0306312713501407.

8. Jankó F, Móricz N, Papp Vancsó J. Reviewing the climate change reviewers: Exploring controversy through report references and citations. Geoforum 2014, 56:17-34. 
9. Lang C. Amazongate: IPCC, climate denial and climate science. REDD-Monitor 2010.

10. Google Trends - Web Search interest - Worldwide, 2004 - present. Available at: https://www.google.co.uk/trends/explore\#q=climate\%20change\%2C\%20global\%20 warming. (Accessed May 29)

11. Collins L, Nerlich B. Examining user comments for deliberative democracy: a corpusdriven analysis of the climate change debate online. Environmental Communication: A Journal of Nature and Culture 2014, 9:189-207.

12. Hulme M, Ravetz J. 'Show Your Working': What 'ClimateGate' means. BBC 2009.

13. Edwards T. Climate scientists must not advocate particular policies. Available at:

14. Schmidt GA. What should climate scientists advocate for? Bulletin of the Atomic Scientists 2015, 71:70-74.

15. McCright AM, Dunlap RE. The politicization of climate change and polarization in the american public's views of global warming, 2001-2010. Sociological Quarterly 2011, 52:155-194.

16. Painter J. Poles Apart: The International Reporting of Climate Scepticism. 2011, Page 136.

17. Anderson AA, Brossard D, Scheufele DA, Xenos MA, Ladwig P. The "nasty effect:" online incivility and risk perceptions of emerging technologies. Journal of ComputerMediated Communication 2014, 19:373-387.

18. Pielke Jr RA. The Honest Broker: Making Sense of Science in Policy and Politics: Cambridge University Press; 2007.

19. Rapley CG, de Meyer K, Carney J, Clarke R, Howarth C, Smith N, Stilgoe J, Youngs S, Brierley C, Haugvaldstad A, et al. "Time for Change? Climate Science Reconsidered", Report of the UCL Policy Commission on Communicating Climate Science. 2014.

20. Wibeck V. Enhancing learning, communication and public engagement about climate change - some lessons from recent literature. Environmental Education Research 2014, 20:387-411.

21. Andrews K, Boykoff M, Daly M, Gifford L, Luedecke G, McAllister L, Nacu-Schmidt A, Wang X. World Newspaper Coverage of Climate Change or Global Warming, 20042015. 2015.

22. Schäfer MS, Schlichting I. Media representations of climate change: a meta-analysis of the research field. Environmental Communication: A Journal of Nature and Culture 2014, 8:142-160.

23. Schmidt A, Ivanova A, Schäfer MS. Media attention for climate change around the world: A comparative analysis of newspaper coverage in 27 countries. Global Environmental Change 2013, 23:1233-1248.

24. Romm J. Silence Of The Lambs: Climate Coverage Drops At Major U.S. Newspapers, Flatlines On TV. ThinkProgress.

25. Nerlich B, Forsyth R, Clarke D. Climate in the news: how differences in media discourse between the US and UK reflect national priorities. Environmental Communication: A Journal of Nature and Culture 2012, 6:44-63.

26. Grundmann R, Scott M. Disputed climate science in the media: Do countries matter? Public Understanding of Science 2014, 23:220-235.

27. Jaspal R, Nerlich B. When climate science became climate politics: British media representations of climate change in 1988. Public Understanding of Science 2014, 23:122-141.

28. Kirilenko AP, Stepchenkova SO. Climate change discourse in mass media: application of computer-assisted content analysis. Journal of Environmental Studies and Sciences 2012, 2:178-191.

29. Mazur A. How did the fracking controversy emerge in the period 2010-2012? Public Understanding of Science 2014. 
30. Howell R, Shackley, S., Mabon, L., Ashworth, P. \& Jeanneret, T. . Engaging the public with low-carbon energy technologies: Results from a Scottish large group process. Energy Policy 2014, 66:496-506.

31. Nerlich B, Jaspal R. Metaphors we die by? Geoengineering, metaphors, and the argument from catastrophe. Metaphor and Symbol 2012, 27:131-147.

32. Nerlich B, Jaspal R. UK media representations of Carbon Capture and Storage: Actors, frames and metaphors. Metaphor and the Social World 2013, 3:35-53.

33. Jaspal R, Nerlich B. Fracking in the UK press: Threat dynamics in an unfolding debate. Public Understanding of Science 2014, 23:348-363.

34. Jaspal R, Nerlich B, Lemańcyzk S. Fracking in the Polish press: Geopolitics and national identity. Energy Policy 2014, 74:253-261.

35. Jaspal R, Turner A, Nerlich B. Fracking on YouTube: Exploring Risks, Benefits and Human Values. Environmental Values 2014, 23:501-527.

36. O'Neill SJ, Smith N. Climate change and visual imagery. Wiley Interdisciplinary Reviews: Climate Change 2014, 5:73-87.

37. Hollin G, Pearce W. Tension between scientific certainty and meaning complicates communication of IPCC reports. Nature Climate Change 2015, 5.

38. Carvalho A, Burgess J. Cultural circuits of climate change in U.K. broadsheet newspapers, 1985-2003. Risk Analysis: An Official Publication of the Society for Risk Analysis 2005, 25:1457-1469.

39. Pearce W. Scientific data and its limits: rethinking the use of evidence in local climate change policy. Evidence \& Policy: A Journal of Research, Debate and Practice 2014, 10:187-203.

40. Hawkins E, Edwards T, McNeall D. Pause for thought. Nature Climate Change 2014, 4:154-156.

41. Betts R. Widening the climate conversation. Soapbox Science 2012.

42. Koteyko N, Nerlich B, Hellsten I. Climate Change Communication and the Internet: Challenges and Opportunities for Research. Environmental Communication: $A$ Journal of Nature and Culture 2015, 9:149-152.

43. Koteyko N. Mining the internet for linguistic and social data: An analysis of 'carbon compounds' in Web feeds. Discourse \& Society 2010, 21:655-674.

44. Koteyko N. Corpus-assisted analysis of Internet-based discourses: From patterns to rhetoric. In: Ridolfo J, Hart-Davidson W, eds. Rhetoric and Digital Humanities. Chicago: University of Chicago Press; 2015.

45. Koteyko N, Thelwall M, Nerlich B. From carbon markets to carbon morality: creative compounds as framing devices in online discourses on climate change mitigation. Science Communication 2010, 32:25 -54.

46. Jang SM, Hart PS. Polarized frames on "climate change" and "global warming" across countries and states: Evidence from Twitter big data. Global Environmental Change 2015, 32:11-17.

47. Hellsten I, Vasileiadou E. The creation of the climategate hype in blogs and newspapers: mixed methods approach. Internet Research 2015, 25.

48. Sharman A. Mapping the climate sceptical blogosphere. Global Environmental Change 2014, 26:159-170.

49. Elgesem D, Steskal L, Diakopoulos N. Structure and content of the discourse on climate change in the blogosphere: the big picture. Environmental Communication 2014, 9:169-188.

50. Matthews P. Why are people skeptical about climate change? Some insights from blog comments. Environmental Communication 2015, 9:153-168.

51. Koteyko N, Jaspal R, Nerlich B. Climate change and 'climategate' in online reader comments: a mixed methods study. The Geographical Journal 2013, 179:74-86. 
52. Nerlich B. Moderation impossible? On hype, honesty and trust in the context of modern academic life. The Sociological Review 2013, 61:43-57.

53. Porter AJ, Hellsten I. Investigating participatory dynamics through social media using a multideterminant "frame" approach: the case of Climategate on YouTube. Journal of Computer-Mediated Communication 2014, 19:1024-1041.

54. Schäfer MS. Online communication on climate change and climate politics: a literature review. Wiley Interdisciplinary Reviews: Climate Change 2012, 3:527-543.

55. Schmidt G. To blog or not to blog? Nature Geoscience 2008, 1:208-208.

56. Pearce W, Holmberg K, Hellsten I, Nerlich B. Climate Change on Twitter: Topics, Communities and Conversations about the 2013 IPCC Working Group 1 Report. PLoS ONE 2014, 9:e94785.

57. Williams HTP, McMurray JR, Kurz T, Lambert FH. Network analysis reveals open forums and echo chambers in social media discussions of climate change. Global Environmental Change 2015, 32:126-138.

58. boyd d, Crawford K. Critical Questions for Big Data. Information, Communication \& Society 2012, 15:662-679.

59. Capstick SB, Pidgeon NF. What is climate change scepticism? Examination of the concept using a mixed methods study of the UK public. Global Environmental Change 2014, 24:389-401.

60. Cook J, Lewandowsky S. The Debunking Handbook. St. Lucia, Australia: University of Queensland; 2011.

61. Watts A. An extraordinary meeting of climate skeptics and climate scientists in Bath. Watts Up With That? 2014.

62. Yeo $S$. Climate consensus: scientists and sceptics suspend hostilities. Available at:

63. Bain PG, Hornsey MJ, Bongiorno R, Jeffries C. Promoting pro-environmental action in climate change deniers. Nature Climate Change 2012, 2:600-603.

64. Stern PC. Psychology: Fear and hope in climate messages. Nature Climate Change 2012, 2:572-573.

65. Feinberg $M$, Willer R. Apocalypse soon? Dire messages reduce belief in global warming by contradicting just-world beliefs. Psychological Science 2011, 22:34-38.

66. Hart PS, Nisbet EC. Boomerang effects in science communication how motivated reasoning and identity cues amplify opinion polarization about climate mitigation policies. Communication Research 2012, 39:701-723.

67. Kahan DM, Peters E, Wittlin M, Slovic P, Ouellette LL, Braman D, Mandel G. The polarizing impact of science literacy and numeracy on perceived climate change risks. Nature Climate Change 2012, 2:732-735.

68. Shome D, Marx S. The psychology of climate change communication. Center for Research on Environmental Decisions. Columbia University 2009.

69. Leiserowitz A. Weather, climate, and (especially) society. Weather, Climate, and Society 2012, 4:87-89.

70. Climate Communication

Available at: https://www.climatecommunication.org/. (Accessed May 28)

71. Climate Outreach and Information Network. Available at: www.climateoutreach.org.uk. (Accessed May 28)

72. Talking Climate. Available at: talkingclimate.org. (Accessed May 28)

73. Jasanoff $\mathrm{S}$. What is the regulatory science? Concept and history in United States and in Japan. Clinical Evaluation 2011, 39:167-180.

74. Brown MB. Politicizing science: Conceptions of politics in science and technology studies. Social Studies of Science 2015, 45:3-30.

75. Sarewitz D. Does climate change knowledge really matter? Wiley Interdisciplinary Reviews: Climate Change 2011, 2:475-481. 
76. Rockström J, Brasseur G, Hoskins B, Lucht W, Schellnhuber J, Kabat P, Nakicenovic N, Gong $\mathrm{P}$, Schlosser P, Costa MM, et al. Climate change: the necessary, the possible and the desirable. Earth's Future 2014.

77. Cook J, Nuccitelli D, Green SA, Richardson M, Winkler B, Painting R, Way R, Jacobs P, Skuce A. Quantifying the consensus on anthropogenic global warming in the scientific literature. Environmental Research Letters 2013, 8:024024.

78. The Consensus Project: About. Available at: http://theconsensusproject.com/. (Accessed May 28)

79. Abraham J, Nuccitelli D. Climate Consensus - the $97 \%$. Available at:

80. Kelly H. John Oliver and Bill Nye Show the World How to Debate with Climate Change Deniers. The New Republic 2014.

81. Obama B. Ninety-seven percent of scientists agree: \#climate change is real, manmade and dangerous. Read more: http://OFA.BO/gJsdFp. @BarackObama 2013. Vol. 2015, Page May 28. Available at:

https://twitter.com/BarackObama/status/335089477296988160.

82. Cook J. Closing the consensus gap: Public support for climate policy. Available at:

83. Ding D, Maibach EW, Zhao X, Roser-Renouf C, Leiserowitz A. Support for climate policy and societal action are linked to perceptions about scientific agreement. Nature Climate Change 2011, 1:462-466.

84. Lewandowsky S, Gignac GE, Vaughan S. The pivotal role of perceived scientific consensus in acceptance of science. Nature Climate Change 2013, 3:399-404.

85. Media Coverage of The Consensus Project. Available at:

86. Oreskes N, Conway EM. Merchants of Doubt: How a Handful of Scientists Obscured the Truth on Issues from Tobacco Smoke to Global Warming. New York: Bloomsbury; 2010.

87. Corner A, Whitmarsh L, Xenias D. Uncertainty, scepticism and attitudes towards climate change: Biased assimilation and attitude polarisation. Climatic Change 2012, 114:463-478.

88. Lejano RP, Tavares-Reager J, Berkes F. Climate and narrative: Environmental knowledge in everyday life. Environmental Science \& Policy 2013, 31:61-70.

89. Kahan DM. Climate-science communication and the measurement problem. Advances in Political Psychology 2015, 36:1-43.

90. Oreskes N. The scientific consensus on climate change. Science 2004, 306:16861686.

91. Bray D. The scientific consensus of climate change revisited. Environmental Science and Policy 2010, 13:340-350.

92. Anderegg WRL, Prall JW, Harold J, Schneider SH. Expert credibility in climate change. Proceedings of the National Academy of Sciences 2010, 107:12107-12109.

93. Doran PT, Zimmerman MK. Examining the scientific consensus on climate change. Eos, Transactions American Geophysical Union 2009, 90:22.

94. Climate Change Act 2008. Chapter 27.

95. Demeritt D. Science studies, climate change and the prospects for constructivist critique. Economy and Society 2006, 35:453-479.

96. Chen $\mathrm{X}$, Tung K-K. Varying planetary heat sink led to global-warming slowdown and acceleration. Science 2014, 345:897-903.

97. Ridley DA, Solomon S, Barnes JE, Burlakov VD, Deshler T, Dolgii SI, Herber AB, Nagai T, Neely RR, Nevzorov AV, et al. Total volcanic stratospheric aerosol optical depths and implications for global climate change. Geophysical Research Letters 2014, 41:2014GL061541.

98. Marotzke J, Forster PM. Forcing, feedback and internal variability in global temperature trends. Nature 2015, 517:565-570. 
99. Machin A. Negotiating Climate Change: Radical Democracy and the Illusion of Consensus. London: Zed Books; 2013.

100. Corner A. A new conversation with the centre-right about climate change: Values, frames and narratives. 2013.

101. Corner A, van Eck C. Science \& Stories: Bringing the IPCC to Life. 2014.

102. Decisions CfRoE, ecoAmerica. Connecting on Climate: A Guide to Effective Climate Change Communication. 2014.

103. Landström C, Hauxwell-Baldwin R, Lorenzoni I, Rogers-Hayden T. The (mis)understanding of scientific uncertainty? How experts view policy-makers, the media and publics. Science as Culture 2015:1-23.

104. Society R. The Public Understanding of Science. 1985.

105. Hassol SJ. Improving how scientists communicate about climate change. Eos, Transactions American Geophysical Union 2008, 89:106-107.

106. Somerville RC, Hassol SJ. Communicating the science of climate change. Physics Today 2011, 64:48-53.

107. Myers T, Maibach EW, Peters E, Leiserowitz A. Simple messages help set the record straight about scientific agreement on human-caused climate change: The results of two experiments. PLOS ONE 2015, e0120985.

108. Wynne B. Public uptake of science: a case for institutional reflexivity. Public Understanding of Science 1993, 2:321-337.

109. Wynne B. Public engagement as a means of restoring public trust in science: hitting the notes, but missing the music? Community Genetics 2006, 9:211-220.

110. Cooke B, Kothari U. Participation: the New Tyranny? New York: Zed Books; 2001.

111. Felt U, Wynne B. Taking European Knowledge Society Seriously. 2007.

112. Stirling A. "Opening Up" and "Closing Down" Power, Participation, and Pluralism in the Social Appraisal of Technology. Science, Technology \& Human Values 2008, 33:262-294.

113. Wynne B. Further disorientation in the hall of mirrors. Public Understanding of Science 2014, 23:60-70.

114. de Melo-Martín I, Intemann K. Who's Afraid of Dissent? Addressing Concerns about Undermining Scientific Consensus in Public Policy Developments. Perspectives on Science 2014, 22:593-615.

115. Committee HoCSaT. Communicating Climate Science. 2014.

116. Wynne B. Strange weather, again climate science as political art. Theory, Culture \& Society 2010, 27:289-305.

117. Edwards T. How to love uncertainty in climate science. All Models Are Wrong.

118. Slingo J, Belcher S, Scaife A, Smith D, Knight J, Hermanson L, Palmer M, Andrews M. Latest Decadal Forecast 2014-2018. 2014.

119. Mann ME. Earth Will Cross the Climate Danger Threshold by 2036. Available at:

120. Lewandowsky S, Oreskes N, Risbey JS, Newell BR, Smithson M. Seepage: Climate change denial and its effect on the scientific community. Global Environmental Change 2015, 33:1-13.

121. Gilbert N, Mulkay M. Opening Pandora's Box: A Sociological Analysis of Scientists' Discourse. Cambridge: Cambridge University Press; 1984.

122. Boykoff MT. Media discourse on the climate slowdown. Nature Climate Change 2014, 4:156-158.

123. Welsh I, Wynne B. Science, scientism and imaginaries of publics in the UK: passive objects, incipient threats. Science as Culture 2013, 22:540-566.

124. Auer MR, Zhang Y, Lee $P$. The potential of microblogs for the study of public perceptions of climate change. Wiley Interdisciplinary Reviews: Climate Change 2014, 5:291-296. 
125. Whitmarsh L. What's in a name? Commonalities and differences in public understanding of "climate change" and "global warming". Public Understanding of Science 2009, 18:401-420.

126. Hulme M. The conquering of climate: discourses of fear and their dissolution. The Geographical Journal 2008, 174:5-16.

127. Darier É, Schüle R. Think globally, act locally'? Climate change and public participation in Manchester and Frankfurt. Local Environment 1999, 4:317-329.

128. Bostrom A, Morgan MG, Fischhoff B, Read D. What do people know about global climate change? 1. Mental models. Risk Analysis 1994, 14:959-970.

129. Read D, Bostrom A, Morgan MG, Fischhoff B, Smuts T. What do people know about global climate change? 2. Survey studies of educated laypeople. Risk Analysis 1994, 14:971-982.

130. Pidgeon NF, Lorenzoni I, Poortinga W. Climate change or nuclear power-No thanks! A quantitative study of public perceptions and risk framing in Britain. Global Environmental Change 2008, 18:69-85.

131. Lorenzoni I, Pidgeon NF. Public Views on Climate Change: European and USA Perspectives. Climatic Change 2006, 77:73-95.

132. Spence A, Pidgeon N, Uzzell D. Climate change - psychology's contribution. The Psychologist 2009, Pages 108-111.

133. Lorenzoni I, Hulme M. Believing is seeing: laypeople's views of future socioeconomic and climate change in England and in Italy. Public Understanding of Science 2009, 18:383-400.

134. Dryzek JS. Deliberative Democracy and Beyond: Liberals, Critics, Contestations. Oxford: Oxford University Press; 2000.

135. Fischer F. Citizens, Experts, and the Environment: The Politics of Local Knowledge. Durham: Duke University Press; 2000.

136. Jasanoff S. States of Knowledge: The Co-Production of Science and the Social Order. London: Routledge; 2006.

137. Mouffe C. On the political. Abingdon: Routledge; 2005. 